\title{
City Marketing, Aspectos Culturais e Relações Simbólicas na Construção da Imagem-Marca de Cidades
}

\author{
City marketing, cultural aspects and symbolic relations in the construction of brand \\ image of cities
}

Francine da Silva Pujol - Universidade Federal do Pampa | São Borja | RS | Brasil | Email: franpujol@gmail.com | https://orcid.org/0000-0002-3299-1895

Renata Patricia Corrêa Coutinho - Universidade Federal do Pampa | São Borja | RS |

Brasil | E-mail: renatacorreacoutinho@gmail.com | http://orcid.org/0000-0002-98325836

Resumo: As cidades nunca cresceram tanto como hoje, através de uma esfera cultural, num processo que modifica os próprios conceitos de cultura e de cidade, unindo, desse modo, como até então não acontecera, a economia política da cultura e a economia política do lugar. O city marketing é uma ferramenta poderosa de difusão de discurso, já que o marketing urbano permite identificar as estreitas relações entre os campos de cultura, da comunicação e da política, que nela atuam para tornar hegemônicas determinadas leituras do espaço. O presente estudo tem por objetivo entender o conceito de city marketing, compreender o uso desta ferramenta para a manutenção da marca das cidades, e também, objetiva contribuir para a construção de conhecimento acerca da importância e do papel da cultura no processo de gestão da imagem e da construção simbólica da identidade das cidades e da promoção delas. A pesquisa caracteriza-se como exploratória e a pesquisa bibliográfica será o método utilizado para seu desenvolvimento.

Palavras-chave: City Marketing. Marca de lugares. Cidades. Cultura. Marca.

Abstract: Cities have never grown as much as they do today, through a cultural sphere, in a process that modifies the very concepts of culture and city, thus uniting the political economy of culture and the political economy of place. City marketing is a powerful discourse diffusion tool, as urban marketing allows us to identify the close relationships between the fields of culture, communication and politics, which act in it to make certain readings of space hegemonic. This study aims to understand the concept of city marketing, to understand the use of this tool to maintain the brand of cities, and also aims to contribute to the construction of knowledge about the importance and role of culture in the image management process and the symbolic construction of the identity of cities and their promotion. Research is characterized as exploratory and bibliographic research will be the method used for its development.

Keywords: City marketing. Mark of places. Cities. Culture. Brand.

- Recebido em: 28 out. 2019 - Aprovado em: 02 dez. $2019 \bullet$ e-ISSN: 2177-5788

DOI: https://doi.org/10.22484/2177-5788.2019v45n2p359-371

Copyright @ 2019. Conteúdo de acesso aberto, distribuído sob os termos da Licença Internacional da CreativeCommons - CC BY-NC-SA - Atribuição Não Comercial (https://br.creativecommons.org/licencas/) - Permite distribuição e reprodução, desde que atribuam os devido créditos à publicação, ao autor(es) e que licenciem as novas criações sob termos idênticos. 


\section{Introdução}

A partir do presente estudo se pretende entender o conceito de city marketing e compreender o uso desta ferramenta para a manutenção da marca das cidades. Mediante esta pesquisa também será abordada a contribuição e importância da cultura no processo de gestão da imagem na construção da identidade das cidades e da promoção delas.

O city marketing, conforme Sánchez (1999), se constitui na orientação da política urbana à criação ou ao atendimento das necessidades do consumidor, seja este empresário, turista ou o próprio cidadão. Macedo (2002) corrobora com este conceito e o amplia quando diz que o city marketing tem por objetivo estimular determinadas atividades locais e reforça que normalmente é utilizado para alterar as percepções externas de uma cidade com o objetivo de incentivar o turismo, atrair a migração interna dos moradores ou permitir o investimento empresarial.

Além de promover a cidade para o público externo, o city marketing, para Scheidt Júnior et al. (2015), também objetiva atingir os próprios habitantes bem como os possíveis e eventuais investidores. Através da construção de uma nova imagem da cidade, dotada de um forte impacto social, a cidade deixa de ser um lugar do cidadão e passa a ser daquele que tem direito a ela, aquele que mora na cidade, o citadino. Contemplando, também, as necessidades e os desejos da comunidade local, segundo Ocke e Ikeda (2014), o processo tende a receber maior índice de aprovação e aderência dos nativos que, por sua vez, se tornaram mais ativos em todas as etapas de formulação, elaboração e implementação de uma estratégia de marketing de lugar.

As cidades, tal como os produtos estão sujeitas a forças internas e externas e a variações cíclicas, que eventualmente se traduzem em períodos de maior ou menor prosperidade, de vitalidade ou decadência. Ainda assim, segundo Moreira e Silva (2015), baseando-se em Kotler, REU, Sorocaba, SP, v. 45, n. 2, p. 445-461, dez. 2019. 
Haider e Rein (1994), a prosperidade ou decadência de uma cidade extrapola as medidas fiscais e econômicas, pois as cidades são muito mais do que orçamentos ou negócios, envolvem pessoas, culturas, heranças históricas, patrimônio físico e oportunidades.

Recorrendo a conceitos como os já trazidos até o momento é que se pretende compreender o conceito de city marketing, as possibilidades de seu uso e aplicação e de que maneira ela pode contribuir na manutenção/construção da imagem-marca das cidades. Além disso, também se pretende verificar as conexões existentes entre a construção significativa da imagem-marca das cidades e a relação desta com os aspectos culturais presentes nestes cenários urbanos.

Acerca da metodologia escolhida para o desenvolvimento do presente artigo, recorremos a Vergara (2007), que considera que os tipos de pesquisa podem ser definidos pelos critérios quanto aos fins e quanto aos meios. Sendo assim, quanto aos fins, esta pesquisa caracteriza-se como sendo exploratória, e quanto aos meios pode ser considerada bibliográfica, já que para o embasamento do estudo recorreremos às fontes bibliográficas. Com relação ao método a ser adotado para o desenrolar do presente artigo, consideramos que será o indutivo, que de acordo com Gil (2008), é caracterizada como um tipo de metodologia que parte da observação de fatos ou fenômenos cujas causas se deseja conhecer.

\section{Conceitos Introdutórios: marketing e marca}

$\mathrm{Na}$ introdução alguns conceitos a respeito do marketing de lugares ou city marketing já foram apresentados. Porém, antes de recorremos a mais conceitos sobre este tema, se entende que é preciso compreender o conceito básico de Marketing, a fim de colaborar para que seja estabelecida a linha de compreensão e a formatação das articulações do presente trabalho.

Ao tratar sobre o conceito de Marketing é imprescindível citar Phillip Kotler (2006). O estudioso é considerado "pai" ou "papa" do marketing e 
teve sua primeira obra publicada no final da década de 1960, intitulada Administração de Marketing, considerada a "Bíblia do Marketing". O livro já conta com mais de uma dezena de edições e desde sua $12^{a}$ conta com coautoria do professor Kevin Lane Keller (2006), outro respeitado estudioso da área do marketing e que é reconhecido por sua contribuição na teorização da Gestão de Marcas ou Branding, área que faz parte do estudo do marketing e que também será referenciada, em breve, nesta mesma seção quando for abordado o conceito de marca.

Para Kotler e Keller (2006), por marketing se entende a ação de criar, promover e fornecer bens e serviços a clientes, sejam eles pessoas físicas ou jurídicas. Os autores também recorrem ao conceito estabelecido pela American Markerting Association (AMA).

O marketing é uma função organizacional e um conjunto de processos que envolvem a criação, a comunicação e a entrega de valor para os clientes, bem como a administração do relacionamento com eles, de modo que beneficie a organização e seu público interessado (AMERICAN MARKETING ASSOCIATION apud KOTLER; KELLER, 2006, p. 4).

Cobra (2009) diz que a essência do marketing está nas trocas, ou seja, no processo pelo qual duas ou mais partes oferecem algo de valor para o outro e que tem como objetivo a satisfação de necessidades e desejos. Para o autor, a troca é o conceito central do marketing e esta pode ser monetária ou não, e existirá sempre que houver, ao menos, duas partes negociando.

A respeito de como o Marketing pode ser desenvolvido e para o que, Kotler e Keller (2006) apontam que seu conceito e ferramentas podem ser aplicados para de bens, serviços, experiências, eventos, pessoas, lugares, organizações, informações e ideias (Quadro 1).

Quadro 1 - Aplicação de Marketing

\begin{tabular}{|l|l|}
\hline \multicolumn{2}{|c|}{ A que se aplica o Marketing? } \\
\hline BENS & Bens tangíveis ou produtos; \\
\hline SERVIÇOS & $\begin{array}{l}\text { Produção de serviços; Serviços como os prestados por empresas ou } \\
\text { profissionais liberais; Muitas ofertas consistem em um mix variável }\end{array}$ \\
\hline
\end{tabular}

REU, Sorocaba, SP, v. 45, n. 2, p. 359-371, dez. 2019. 


\begin{tabular}{|l|l|}
\hline & entre bens e serviços. \\
\hline EVENTOS & $\begin{array}{l}\text { Eventos como feiras setoriais, espetáculos artísticos, comemorações } \\
\text { de aniversário, eventos esportivos. }\end{array}$ \\
\hline EXPERIÊNCIAS & $\begin{array}{l}\text { Orquestrando diversos serviços e mercadorias é criada, apresentada } \\
\text { e comercializada a experiência. Experiências customizadas. }\end{array}$ \\
\hline PESSOAS & $\begin{array}{l}\text { Marketing de celebridades; Relações públicas para artistas, músicos, } \\
\text { presidentes de empresas, médicos, advogados e financistas bem- } \\
\text { sucedidos; Marketing pessoal: tornar a pessoa em uma "marca". }\end{array}$ \\
\hline LUGARES & $\begin{array}{l}\text { Lugares - cidades, estados, regiões e países inteiros competem para } \\
\text { atrair turistas, fábricas, sedes de empresas e novos moradores. }\end{array}$ \\
\hline PROPRIEDADES & $\begin{array}{l}\text { Propriedades são direitos intangíveis de posse, tanto de imóveis como } \\
\text { de bens financeiros (ações e títulos). Imobiliárias, instituições de } \\
\text { investimentos e bancárias. }\end{array}$ \\
\hline ORGANIZAÇÕES & $\begin{array}{l}\text { Organizações trabalham sistematicamente para construir uma } \\
\text { imagem sólida e positiva na mente de seu público-alvo; Identidade } \\
\text { corporativa; Universidades, museus, grupos de teatro e organizações } \\
\text { sem fim lucrativos usam o marketing para melhorar sua imagem } \\
\text { pública e competir por público e recursos. }\end{array}$ \\
\hline INFORMAÇÕES & $\begin{array}{l}\text { Informações podem ser produzidas e comercializadas como um } \\
\text { produto. Produção, embalagem e distribuição de informações. }\end{array}$ \\
\hline IDEIAS & $\begin{array}{l}\text { Toda oferta de marketing traz em sua essência uma ideia básica; } \\
\text { Produtos e serviços são plataformas na entrega de algum conceito ou } \\
\text { beneficio. }\end{array}$ \\
\hline
\end{tabular}

Fonte: Adaptado de Kotler e Kotler (2006, p. 6-7).

Para conceituar marca, Keller e Machado (2006) recorrem também aos insumos teóricos oferecidos pela AMA. A associação conceitualiza a marca como "nome, termo, símbolo, desenho ou uma combinação desses elementos que deve identificar os bens ou serviços de um fornecedor ou grupo de fornecedores e diferenciá-los dos da concorrência" (KELLER; MACHADO, 2006, p. 2). Kotler e Armstrong (2007, p. 210) contribuem para esta abordagem e a ampliam quando dizem que:

As marcas são muito mais que meros nomes e símbolos. Elas são um elemento-chave nas relações da empresa com os consumidores. As marcas representam as percepções e os sentimentos dos consumidores com relação a um produto e seu desempenho, tudo o que o produto ou serviço significa para os consumidores.

\section{City Marketing e Estetização}

Se mencionamos Kotler como sendo referência máxima no que se trata por Marketing, quando o assunto é a estetização, não só das cidades, mas do mundo, Lipovetsky e Serroy (2015) são as "autoridades" em questão e, por isso, são presenças ilustres nas referências que compõem este trabalho. Na obra A Estetização do Mundo, os autores contemplam, 
relacionam e ampliam a conceptualização de city marketing. Na citação a seguir, é possível compreender que papel está exercendo o papel estético na promoção dos espaços urbanos na atualidade.

Assiste-se a um vasto trabalho de requalificação e de estetização dos centros urbanos, o que é atestado pelo espaço cada vez maior dado à "visual delectation", ao design dos espaços públicos e do mobiliário urbano, ao fachadismo arquitetônico, à revalorização do patrimônio, à multiplicação dos museus, à edificação de construções de tirar o fôlego, projetadas por arquitetos estrela. No contexto hipermoderno, em que existe uma forte concorrência entre as cidades para se destacar em atrativos, a dimensão estética se tornou um fator-chave destinado a incentivar o turismo, atrair os investidores, os organizadores de congressos, a nova classe dos "manipuladores de símbolo". A época assiste ao desenvolvimento da mise-en-scène da cidade e do city marketing, e as cidades se empenham num trabalho de identidade visual, de imagem e de comunicação para conquistar "fatias de mercado", tal como as marcas comerciais (LIPOVETSKY; SERROY, 2015, p. 224-25).

$\mathrm{Na}$ introdução foram trazidos alguns conceitos básicos e descritivos acerca do city marketing ou marketing de lugar. Considerada uma ferramenta poderosa de difusão de discurso, este tipo de marketing urbano permite identificar as estreitas relações entre os campos de cultura, da comunicação e da política, que nela atuam para tornar hegemônica determinadas leituras do espaço. Essa combinação se dá pelos meios de comunicação e informação. Sendo veículos de construção ideológica, conforme Sánchez (2001), os meios atuam como aceleradores culturais, definem e revelam traços do espírito da época.

Wielewicki (2011) justifica a adoção dessa abordagem de marketing, tradicionalmente utilizada no domínio dos bens e serviços de consumo, na promoção das cidades, devido ao ambiente fortemente competitivo que caracteriza os lugares no que diz respeito à sua disputa para atrair investimentos, residentes e visitantes. Afinal, segundo Keller e Machado (2006), dentre as metas do Marketing de cidades está a de criar conhecimento sobre uma cidade com vistas a construção de uma imagem favorável da localidade, de modo que induza visitas temporárias ou mudanças permanentes tanto de pessoas como de empresas. 
O marketing de lugares tem como principal finalidade orientar as cidades para afirmar e reforçar sua identidade, através da valorização do patrimônio cultural composto por bens tangíveis e intangíveis, visando a sua promoção. No entanto, conforme Pinto e Meneses (2010), se faz necessário colocar a população local como elemento fundamental das estratégias do marketing de lugares, para evitar o risco da segregação social do espaço urbano, comprometendo assim as relações sociais cotidianas.

Uma cidade é potencialmente uma "experiência sensorial e emocional" (LANDRY, 2006, p. 2 apud GUERREIRO, 2009, p. 4). Guerreiro complementa, ainda, dizendo que a identidade, o caráter e a personalidade são construções abstratas, embora baseadas na realidade, que se relacionam a atributos diferenciadores em sintonia aos quais os seus públicos desenvolvem laços afetivos.

\subsection{Gestão de marca das cidades}

Assim como produtos e pessoas, localidades geográficas também podem ter marcas, de acordo com Keller e Machado (2006). Os autores pontuam que, nesse caso, o nome da marca é o próprio nome da cidade e compete ao branding fazer com que as pessoas se lembrem da localidade e façam associações desejáveis com ela.

Kotler, Haider e Rein (1994) revelam que a estratégia de marketing de imagem é a mais barata quando comparada a outras estratégias, como o marketing de atrações, de infraestrutura ou de pessoas, uma vez que, quando uma localidade desenvolve essa estratégia, ela não investe dinheiro para melhorar infraestrutura e promover atrações, mas apenas "comunica" as pessoas sobre suas características atuais. Nessa situação, o custo e a eficácia da estratégia dependem da imagem atual e dos reais atributos do local. Por isso, o investimento no desenvolvimento de uma imagem-marca bem estruturada de uma cidade se faz tão importante no cenário atual. Não é à toa que Pinto e Meneses (2010) destacam que a identidade da cidade é 
um aspecto chave a ser considerado na estratégia do marketing de lugares, pois revela seu particularismo, reflexo dos recursos materiais e imateriais integrados ao mesmo tempo que oferece um diferencial a uma cidade perante as demais, assegura, sobretudo, a valorização do patrimônio cultural e o bem-estar da comunidade.

Uma boa forma de desenvolver imagem-marca de cidades é recorrer aos modelos compreendidos no branding para marcas. Tal conceito, segundo Macedo (2002), pode ser adotado e aplicado às cidades através da utilização da gestão da imagem do lugar utilizando uma estratégia de inovação econômica, comercial, social, cultural e política.

Kavaratzis (2004), segundo Guerreiro (2009), considera que essa gestão de marca de cidade se dá em torno de dois eixos principais. Um composto pelos meios utilizados para alcançar vantagem competitiva, aumentar o investimento e o turismo. E outro, atrelado ao desenvolvendo da comunidade, a reforçar a identidade local, a estimular nos cidadãos a identificação com a sua cidade e, consequentemente, evitar a exclusão social.

\subsection{Aspectos culturais e a marca das cidades}

De acordo com Teixeira Lopes (2009), as cidades nunca cresceram tanto como hoje, através de uma esfera cultural, num processo que modifica os próprios conceitos de cultura e de cidade, unindo, desse modo, como até então não acontecera, a economia política da cultura e a economia política do lugar. Guerreiro (2009), por sua vez, releva que a vertente cultural, incluindo desde recursos arquitetônicos e urbanísticos até museus e eventos, tem sido o meio utilizado com frequência na construção e reconstrução das respectivas marcas das cidades.

Ostrower (2007) define cultura como as formas materiais e espirituais com que os indivíduos de um grupo convivem, nas quais atuam e se comunicam e cuja experiência coletiva pode ser transmitida através de vias simbólicas. De acordo com a autora, ela serve de referência a tudo que o 
indivíduo é, faz, comunica. Transpondo este conceito para o universo da cidade, há a possibilidade de entendê-la como sendo o "indivíduo" que "comunica".

Landry (2006), segundo Guerreiro (2009), considera que as cidades necessitam de histórias e de narrativas culturais que sustentem sua identidade. Sob uma perspectiva prática e pontual, Avraham (2004), baseando-se em Wielewick (2010), defende que a imagem de uma cidade tende, em termos genéricos, a ser influenciada por fatores como sua localização e história, seu valor/potencial turístico e cultural, bem como, sua natureza e volume de cobertura pelas mídias, sua beleza natural e patrimonial.

Ao complexo cultural que compõe as cidades, Dencker (2004) denomina patrimônio cultural e o conceitua como sendo um amplo e diversificado conjunto de bens culturais, expressões e fazeres das classes populares, além do tradicional patrimônio histórico e artístico. A identificação do patrimônio cultural tem como instrumento de pesquisa um inventário que busca evidenciar bens tangíveis e intangíveis coletivamente importantes, com a preocupação de relacionar turismo e patrimônio. Lipovetsky e Serroy (2015) reafirmam este conceito quando dizem que a época atual está caracterizada pela valorização do patrimônio histórico. 0 trabalho de conservação histórica, por sua vez, colabora e confere um inegável valor de memória às cidades e costuma representar um meio de também preservar as particularidades étnicos dos locais face da uniformização urbana que ocorre na atualidade.

\subsubsection{Relações simbólicas na marca de cidades}

Qualquer cidade pode oferecer um discurso que articula variados signos. Pinheiro e Silva (2004) consideram que as cidades desenvolveram uma linguagem mediante duas redes diferentes e superpostas. Uma é a física, aquela em que o visitante comum percorre até perder-se na sua 
multiplicidade e fragmentação. A outra é a simbólica que, por outro lado, ordena e exige a interpretação de sinais.

Como linguagem, Kristeva (1969) conceitua o processo de comunicação de uma mensagem entre dois sujeitos falantes, sendo um o destinador ou o emissor, e o outro o destinatário ou o receptor. Conectando este conceito ao das redes de linguagem apresentadas por Pinheiro e Silva (2004), pode-se dizer que a cidade é o sujeito que emite a mensagem e, o visitante, aquele que a recebe. Porém, este último faz com que à mensagem é que cabe ainda compreender. Sendo a cidade composta por um labirinto de caminhos, de veias de espaços rasgadas no espaço, somente a aventura pessoal pode penetrar e estabelecer um labirinto de signos. Para isso, somente com o uso de sua inteligência o visitante poderá decifrar, encontrar sentido ou ordem naquilo que foi comunicado.

Kotler, Haider e Rein (1994) definem que a imagem de um local é o resultado de um conjunto de crenças, ideias e impressões que as pessoas têm em relação a esse lugar. Ou seja: as imagens correspondem a uma simplificação das inúmeras associações e informações ligadas ao local, sendo produto de uma mente que tenta fixar a essência de uma série de dados sobre o mesmo. No que se refere ao processo de produção da imagem das cidades, Leandro (2006) considera que os aspectos simbólicos envolvidos têm o foco cada vez mais centrado no meio e não no sujeito. Além disso, o autor entende que a imagem das cidades tem sido institucionalizada, tendo o marketing urbano como destaque.

Se "ler a cidade" significa ter uma representação de cidade, construir uma imagem de cidade significa também compreender e interpretar e, sobretudo, sintetizar, dada a complexidade do fenômeno observado. Porém, "leituras", no plural, implica que a cidade poder ser representada, ou melhor, imaginada, a partir de diversos olhares. Não há uma única leitura possível, uma vez que segundo Sánchez (2001), aquilo que se vê é resultado também do lugar de onde se olha e de para onde se olha. 
As imagens-síntese são aquelas que se destinam à venda de uma representação desejada da cidade e implicam a negação da possibilidade de existência de outras imagens e de outras leituras. Essas imagens, conforme Sánchez (2001) são tornadas dominantes mediante estratégias discursivas, meios e instrumentos para sua difusão e legitimação em variadas escalas.

\section{Considerações Finais}

O presente trabalho procurou relacionar conceitos acerca da definição de city marketing, estabelecer uso desta ferramenta na manutenção marca das cidades, verificar a contribuição e a importância da cultura no processo de gestão de marcas das cidades e, também, as contribuições possíveis que a linguagem e os recursos simbólicos podem oferecer a este processo.

A partir deste estudo pode-se dizer que fica entendido que a construção da marca de uma cidade é um aspecto chave que compõe a estratégia do marketing de lugares. Afinal, como se pode verificar o city marketing exerce muito mais que um papel destinado à revitalização das áreas urbanas ou simples estetização e promoção das cidades, ele também contribui para, sobretudo, a valorização do patrimônio cultural e o bemestar da comunidade que nela habita. Tais constatações surgem como primeiras impressões e sinalizam oportunidades para o desenvolvimento de outros estudos ou novas articulações a serem estabelecidas tendo em vista os conceitos até aqui apresentados.

O foco do desenvolvimento desta pesquisa esteve, principalmente, na coleta de conceitos a partir da descoberta de referências bibliográficas atuais e que pudessem também agregar maior valor e peso a este trabalho. Por isso, se deu preferência para o uso de citações e referências aos quais se foi possível ter acesso aos originais. Na falta deles ou na dificuldade de encontrá-los, se recorreu a uma fonte secundária de base científica, como artigos acadêmicos, em sua maioria, publicados em anais, eventos, revistas 
científicas ou repositórios de instituições de ensino superior. A partir disso, uma rica gama de referências bibliográficas pode ser estabelecida.

Por fim, concluímos esta etapa vislumbrando uma possível retomada ou continuidade do estudo, tendo em vistas não o aprofundamento teórico, mas sim o tensionamento dos dados conseguidos até aqui, oferecendo uma visão mais crítica e com vistas a construção de novos conhecimentos e conceitos para áreas de conhecimento relacionadas aos temas abordados.

\section{Referências}

COBRA, Marcos. Administração de marketing no Brasil. 3. ed. Rio de Janeiro: Elsevier, 2009.

DENCKER, A. F. M. Métodos e técnicas de pesquisa em turismo. 8. ed. São Paulo: Futura, 2004.

GIL, Antonio Carlos. Métodos e técnicas de pesquisa social. 6. ed. São Paulo: Atlas, 2008.

GUERREIRO, Maria. O papel da Cultura na Gestão da Marca das Cidades. In: CONGRESSO PORTUGUÊS DE SOCIOLOGIA, 4., 2009, Lisboa. Acatas ... Lisboa: Universidade de Lisboa, 2009. p. 1-12.

KELLER, Kevin Lane; MACHADO, Marcos. Gestão estratégica de marcas. São Paulo: Pearson Education do Brasil, 2006.

KOTLER, Philip; ARMSTRONG, Gary. Princípios de marketing. 12. ed. São Paulo: Pearson, 2007.

KOTLER, Philip; HAIDER, Donald H.; REIN, Irving. Marketing público. São Paulo: Makron Books, 1994.

KOTLER, Philip; KELLER, Kevin Lane. Administração de marketing. 12. ed. São Paulo: Prentice Hall, 2006.

KRISTEVA, Julia. História da linguagem. Lisboa: Edições 70, 1969.

LIPOVETSKY, Gilles; SERROY, Jean. A estetização do mundo: viver na era do capitalismo artista. São Paulo: Companhia das Letras, 2015.

LEANDRO, Aldo Gomes. O turismo em João Pessoa e a construção da imagem da cidade. 2006. 195 f. Dissertação (Mestrado em Geografia) Universidade Federal da Paraíba, João Pessoa, 2006.

MACEDO, Luiz Ferreira de. City marketing: uma estratégia para a cidade de Porto Alegre. 2002. 33 f. TCC (Especialização em Marketing) - Universidade Federal do Rio Grande do Sul, Porto Alegre, 2002. Disponível em: http://hdl.handle.net/10183/127228. Acesso em: 1 jun. 2019.

MOREIRA, Jacinta Raquel Miguel Moreira; SILVA, Maria José. Marketing das cidades estudo da identidade: o caso da cidade da Covilha. In: CALVO, Juan Carlos Ayalla (org.). Conocimiento, innovación y emprendedores: camino al futuro. La Rioja: Universidad de La Rioja, 2007. p. 2114-2127. 
OCKE, Marco Antonio de Moraes; IKEDA, Ana Akemi. Marketing de lugar: estado da arte e perspectivas futuras. Revista de Administração, São Paulo, v. 49, n. 4, p. 671-683, 2014. Disponível em:

http://www.scielo.br/scielo.php?pid=S0080-

21072014000400671\&script=sci_abstract\&tlng=pt. Acesso em: 25 mai. 2019.

OSTROWER, Fayga. Criatividade e processos de criação. Petrópolis: Vozes, 2007.

PINHEIRO, Délio José Ferraz; SILVA, Maria Auxiliadora da (orgs.). Visões imaginárias da cidade da Bahia: diálogos entre a geografia e a literatura. Salvador: EDUFBA, 2004.

PINTO, Ana Paula P. G. M.; MENESES, Cecilia M. R. O marketing de lugares e suas implicações na revitalização de áreas urbanas: estudos de casos nas cidades de Belém, Brasil e Arequipa, Peru. In: SEGeT - SIMPÓSIO DE EXCELÊNCIA EM GESTÃO E TECNOLOGIA, 2010, Rezende. [Anais...]. Rezende: Associação Educacional Dom Bosco, 2010.

SÁNCHEZ, Fernanda. A reinvenção das cidades para um mercado mundial. Rev. Sociol. Polít., Curitiba, v. 16, p. 31-49, jun. 2001. Disponível em: http://www.scielo.br/pdf/rsocp/n16/a03n16.pdf. Acesso em: 12 dez. 2019.

SÁNCHEZ, Fernanda. Políticas urbanas em renovação: uma leitura dos modelos emergentes. Revista Brasileira de Estudos Urbanos e Regionais, Campinas, n. 1, p. 115-132, 1999. Disponível em:

https://rbeur.anpur.org.br/rbeur/article/view/13. Acesso em: 12 dez. 2019.

SCHEIDT JUNIOR, Ademar Silva et al. City marketing: identidade competitiva da cidade de Guajará Mirim-RO. In: CONGRESSO NACIONAL DE EXCELÊNCIA EM GESTÃO, 11., 2015, Rio de Janeiro. Anais ... Rio de Janeiro: Firjan, 2015. p. 121. Disponível em: http://www.inovarse.org/sites/default/files/T_15_305.pdf. Acesso em: 12 dez. 2019.

TEIXEIRA LOPES, João. Da democratização da Cultura a um conceito e prática alternativos de Democracia Cultural. Saber \& Educar, Brasil, n. 14, p. 1-13, nov. 2009. Disponível em: https://docplayer.com.br/9147768-Da-cultura-comolocomotiva-da-cidade-empresa-a-um-conceito-alternativo-de-democraciacultural.html. Acesso em: 30 maio 2019.

VERGARA, Sylvia Constant. Projetos e relatórios de pesquisa em administração. 9. ed. São Paulo: Atlas, 2007.

WIELEWICKI, Patrícia Feronha. O estudo das marcas territoriais em prol do desenvolvimento turístico: o caso de Guimarães, capital europeia da cultura em 2012. Caderno Virtual de Turismo, Rio de Janeiro, v. 11, n. 1, p. 134-146, abr. 2011. Disponível em:

http://www.ivt.coppe.ufrj.br/caderno/index.php/caderno/article/download/542/2 73. Acesso em: 12 dez. 2019 